\title{
Association between a microRNA-214 binding site polymorphism in the methylenetetrahydrofolate reductase gene and esophageal squamous cell carcinoma
}

\author{
G.R. Shen ${ }^{1 *}$, W.Z. Li ${ }^{2 *}$, Y.C. $\mathrm{Liu}^{3}$, X.P. $\mathrm{Li}^{1}$ and H.Y. Yuan ${ }^{2}$ \\ ${ }^{1}$ Medical Laboratory Department, \\ The First People's Hospital of Wujiang District, Nantong University, Suzhou, \\ China \\ ${ }^{2}$ Clinical Laboratory Department, Taixing People's Hospital, Taixing, Jiangsu, \\ China \\ ${ }^{3}$ Department of Oncology, Taixing People's Hospital, Taixing, Jiangsu, China \\ *These authors contributed equally to this study. \\ Corresponding author: H.Y. Yuan \\ E-mail: 18151959756@163.com
}

Genet. Mol. Res. 15 (2): gmr. 15028158

Received November 26, 2015

Accepted January 13, 2016

Published May 13, 2016

DOI http://dx.doi.org/10.4238/gmr.15028158

\begin{abstract}
MicroRNAs (miRNAs) are key regulators of gene expression and play an important role in the development and progression of various diseases including esophageal squamous cell carcinoma (ESCC). In this study, we determined whether a polymorphism at the miR-214 binding site in the 3'-untranslated region (3'-UTR) of the methylenetetrahydrofolate reductase gene (MTHFR) is associated with susceptibility to ESCC. A total of 448 ESCC cases and 460 genderand age-matched subjects were recruited for the study. The genotypes of the rs114673809 single nucleotide polymorphism (SNP) were determined by polymerase chain reaction sequencing. Associations between genotypes of MTHFR rs114673809 and ESCC risk were
\end{abstract}


determined using logistic regression analyses. In the recessive model, when the MTHFR rs114673809 GG homozygote genotype was used as the reference group, the GA genotype was not associated with the risk of $\mathrm{ESCC}(\mathrm{GA} v s \mathrm{GG}$ : OR $=1.261,95 \% \mathrm{CI}=0.960-1.657, \mathrm{P}=0.110$ ), but the AA genotype was associated with increased risk of ECSS (AA $v s \mathrm{GG}: \mathrm{OR}=1.752,95 \% \mathrm{CI}=1.076-2.853, \mathrm{P}=0.027$ ). Additionally, the rs114673809 A allele carriers also showed a 1.286-fold increased ESCC risk compared with those carrying the rs114673809 $\mathrm{G}$ allele genotype. Furthermore, we observed a significant increase in plasma homocysteine levels in ESCC cases carrying the AA genotype relative to ESCC cases carrying the GG genotype. Our data demonstrate that a polymorphism at the miR-214 binding site in the $3^{\prime}$-UTR of MTHFR is an ESCC susceptibility SNP in the Chinese population.

Key words: Esophageal squamous cell carcinoma; Polymorphism; Methylenetetrahydrofolate reductase

\section{INTRODUCTION}

Esophageal carcinoma (EC) is a serious threat to human health worldwide; it is the eighth most common human cancer and accounts for the sixth highest rate of cancer mortality. Histologically, EC consists of two major types: esophageal squamous cell carcinoma (ESCC) and esophageal adenocarcinoma (Bandla et al., 2012). Each year, approximately 50\% of newly diagnosed esophageal carcinoma cases occur in China (Holmes and Vaughan, 2007). The carcinogenesis of EC is a complex process that is related to multiple etiologic factors, including dietary factors, infection, alcohol consumption, cigarette smoking, and obesity (Vaughan et al., 1995; Mayne et al., 2001; Wang et al., 2013). However, only a small portion of individuals who have been exposed to the same risk factors develop EC. This suggests that genetic factors play an important role in the development of EC (Fan et al., 2013; Zhang et al., 2013; Ye et al., 2014).

Methylenetetrahydrofolate reductase (MTHFR) is a key regulatory enzyme in folate and homocysteine metabolism, and catalyzes the irreversible conversion of 5,10-methylenetetrahydrofolate to 5-methyltetrahydrofolate, a methyl-group donor in the conversion of homocysteine to methionine. The gene that encodes MTHFR has the chromosomal locus $1 \mathrm{p} 36.3$ and comprises 11 exons. Two common variant genotypes of MTHFR, C677T and A1298C, are associated with a significant reduction in enzyme activity (Martin et al., 2006; Saberi et al., 2012). The MTHFR genotypes 677TT and 1298CC are associated with higher homocysteine levels and lower folate levels, which may lead to DNA hypomethylation and an increased risk of cancer.

MicroRNAs (miRNAs), a class of small (20-22 nucleotide) non-coding RNA molecules, negatively regulate gene expression at the post-transcriptional level by partially binding to complementary sequences in the 3'-untranslated region (3'-UTR) of the targeted mRNA. Recent studies have shown that miRNAs are involved in many biological processes, including cell proliferation, differentiation, cell cycle progression, and apoptosis. Many studies have found that dysregulation of miRNAs is associated with a variety of human diseases including cancer. Owing to their potential effects, single nucleotide polymorphisms 
(SNPs) in pre-miRNA or mature miRNA sequences, or miRNA-binding sites, may modulate miRNA-target interactions and the expression of target genes. SNPs in pre-miRNA or mature miRNA sequences, or miRNA-binding sites have been implicated in cancer susceptibility. For example, an miR-184 binding site polymorphism in TNFAIP2 (rs8126) is associated with the risk of gastric cancer (Xu et al., 2013). A genetic variation in an miR-191 binding site in MDM4 contributes to susceptibility to ESCC (Zhou et al., 2013).

In our previous study, we found an miR-214 binding site SNP (rs114673809) in the 3'UTR region of MTHFR through bioinformatic analysis. However, the role of this polymorphism in MTHFR activity and cancer susceptibility remains unclear. In this study, we explored the association between rs114673809 and susceptibility to ESCC in a Chinese population.

\section{MATERIAL AND METHODS}

\section{Study subjects}

To estimate the association between MTHFR gene polymorphisms and the risk of ESCC, 448 southern Han Chinese patients with ESCC and 460 gender- and age-matched ( \pm 5 years) control subjects were recruited from Wujiang People's Hospital (Wujiang, Jiangsu Province, China) and Taixing People's Hospital (Taixing, Jiangsu Province, China) between January 2013 and October 2015. The control subjects were individuals who went to either hospital for a routine health check and were free from any type of cancer. A written questionnaire was used to obtain demographic and risk factor information, including smoking, alcohol consumption, and family history of malignancy. Smokers were classified as individuals who had smoked at least once during the past 30 days. Individuals were defined as alcohol consumers if they drank alcohol at least once every week. Written informed consent was obtained from all the subjects enrolled in the study. This study was approved by the ethics review boards of Wujiang People's Hospital and Taixing People's Hospital.

\section{DNA extraction and genotyping}

Peripheral blood $(5 \mathrm{~mL})$ was collected from each subject. DNA was obtained from peripheral lymphocytes using a QIAamp DNA Blood Mini Kit (QIAGEN, Valencia, CA, USA) according to the manufacturer instructions. The primers for the polymerase chain reaction (PCR) analysis of MTHFR polymorphism rs114673809 were designed using Primer-BLAST (http://www.ncbi.nlm. nih.gov/tools/primer-blast/) and were synthesized commercially by Sangon Biotech (Shanghai, China). The primer sequences were as follows: forward: 5'-AATCAGCTCCTTGGGACACG-3'; reverse: 5'-CACCCTGGAAAGGGGAGTTG-3'. PCR amplification was performed in a $25-\mu \mathrm{L}$ reaction volume containing $1 \mu \mathrm{L}$ genomic DNA, $2 \mu \mathrm{L} 2.5 \mathrm{mM}$ dNTPs, $2.5 \mu \mathrm{L}$ 10X rTaq buffer, 1 $\mu \mathrm{L}$ each primer $(10 \mathrm{mM})$, and $0.125 \mu \mathrm{LrTaq}$. PCRs were performed under the following conditions: initial denaturation at $94^{\circ} \mathrm{C}$ for $3 \mathrm{~min}$, followed by 30 cycles of $15 \mathrm{~s}$ at $94^{\circ} \mathrm{C}$, annealing at $62^{\circ} \mathrm{C}$ for $10 \mathrm{~s}$, polymerization at $72^{\circ} \mathrm{C}$ for $15 \mathrm{~s}$, with a final polymerization step at $72^{\circ} \mathrm{C}$ for $7 \mathrm{~min}$. The PCR products were purified and sequenced by Sangon Biotech.

\section{Homocysteine determination}

Plasma homocysteine levels were determined using the enzyme immunoassay method 
described by Frantzen et al. (1998) using a commercially available kit from Jianglai Tech Ltd., Shanghai, China.

\section{Statistical analysis}

The distribution differences of the categorical variables between cases and controls were assessed by the chi-square test. A goodness-of-fit chi-square test was used to test the Hardy-Weinberg equilibrium (HWE) of the cancer-free control genotype distributions. Group comparisons were analyzed using the Student $t$-test (two-sided). The association analysis between genetic variants and ESCC risk, and the evaluation of odds ratios (ORs) and 95\% confidence intervals $(95 \% \mathrm{CIs})$ were conducted using unconditional logistic regression, and were adjusted for age and gender. All statistical analyses were performed with the SPSS software (v.12.0) (SPSS Inc., Chicago, IL, USA).

\section{RESULTS}

\section{Characteristics of ESCC patients and controls}

The selected characteristics of the 448 ESCC cases and 460 cancer-free controls are summarized in Table 1. No statistically significant differences were found between the ESCC cases and the healthy controls in terms of age and gender distributions $(P>0.05)$, indicating that the frequency matching was adequate. However, there were more smokers, alcohol consumers, and individuals with a family history of malignancy among the ESCC patients than among the cancer-free control subjects.

Table 1. Distribution of selected characteristics among esophageal squamous cell carcinoma (ESCC) patients and controls.

\begin{tabular}{|c|c|c|c|}
\hline Variable & ESCC patients [N (\%)] $\mathrm{N}=448$ & Controls [N (\%)] N = 460 & $\mathrm{P}$ \\
\hline \multicolumn{3}{|l|}{ Age (years) } & \multirow[t]{3}{*}{0.640} \\
\hline$\leq 59$ & $193(43.1)$ & $206(44.8)$ & \\
\hline$>59$ & $255(56.9)$ & $254(55.2)$ & \\
\hline \multicolumn{3}{|l|}{ Gender } & \multirow[t]{3}{*}{0.608} \\
\hline Female & $125(27.9)$ & $136(29.6)$ & \\
\hline Male & $323(72.1)$ & $324(70.4)$ & \\
\hline \multicolumn{3}{|l|}{ Smoking status } & \multirow[t]{3}{*}{0.038} \\
\hline No & $293(65.4)$ & $331(72.0)$ & \\
\hline Yes & $155(34.6)$ & $129(28.0)$ & \\
\hline \multicolumn{3}{|l|}{ Drinking status } & \multirow[t]{3}{*}{0.011} \\
\hline No & $282(62.9)$ & $327(71.1)$ & \\
\hline Yes & $166(37.1)$ & $133(28.9)$ & \\
\hline \multicolumn{3}{|l|}{ Family history of malignancy } & \multirow[t]{3}{*}{0.000} \\
\hline No & $381(85.0)$ & $428(93.0)$ & \\
\hline Yes & $67(15.0)$ & $32(7.0)$ & \\
\hline
\end{tabular}

\section{Association between the rs114673809 polymorphism and risk of ESCC}

The genotype distributions of the rs114673809 polymorphism in the cases and controls are shown in Table 2. All observed genotype frequencies in both controls and cases conformed to HWE (control: $\chi^{2}=0.814, \mathrm{P}=0.367$; ESCC cases: $\chi^{2}=0.296, \mathrm{P}=0.586$ ). The genotype frequencies of rs 114673809 were $44.0 \%$ (GG), $45.5 \%$ (GA), and $10.5 \%$ (AA) in 
the ESCC patients, and $51.1 \%(\mathrm{GG}), 42.0 \%$ (GA), and $7.0 \%$ (AA) in the control subjects. When the rs114673809 GG homozygote genotype was used as the reference group, the AA genotype was associated with a significantly increased risk of ESCC (AA vs GG: OR $=1.752$, $95 \% \mathrm{CI}=1.076-2.853, \mathrm{P}=0.027)$. However, the GA genotype was not associated with the risk for $\mathrm{ESCC}(\mathrm{GA} v s \mathrm{GG}$ : OR $=1.261,95 \% \mathrm{CI}=0.960-1.657, \mathrm{P}=0.110)$. When the $\mathrm{rs} 114673809$ $\mathrm{G}$ allele was used as the reference group, the $\mathrm{T}$ allele was associated with a significantly increased risk of $\mathrm{ESCC}(\mathrm{A} v s \mathrm{G}: \mathrm{OR}=1.286,95 \% \mathrm{CI}=1.052-1.570, \mathrm{P}=0.014)$.

Table 2. Distribution of rs114673809 polymorphism genotypes in cases and controls.

\begin{tabular}{l|c|c|c|c}
\hline Genotypes & Cases [N (\%)] N=448 & Controls [N (\%)] N=460 & OR (95\%CI) & P \\
\hline GG & $197(44.0)$ & $235(51.1)$ & & 0.110 \\
\hline GA & $204(45.5)$ & $193(42.0)$ & $1.261(0.960-1.657)$ & 0.027 \\
\hline AA & $47(10.5)$ & $32(7.0)$ & $1.752(1.076-2.853)$ & \\
\hline G allele & $598(66.7)$ & $663(72.1)$ & & $1.286(1.052-1.570)$ \\
\hline A allele & $298(33.2)$ & $257(27.9)$ & 0.014 \\
\hline
\end{tabular}

\section{Stratification analyses of MTHFR rs114673809 and risk of ESCC}

We then further evaluated the effect of MTHFR rs114673809 on the risk of ESCC stratified by age, gender, smoking habits, alcohol consumption, and family history of malignancy. As shown in Table 3, the association between MTHFR rs114673809 and the risk of ESCC appeared stronger in the subgroups of younger subjects $(\mathrm{OR}=1.500,95 \% \mathrm{CI}=$ 1.009-2.229, $\mathrm{P}=0.045)$, males $(\mathrm{OR}=1.463,95 \% \mathrm{CI}=1.073-1.996, \mathrm{P}=0.018)$, non-smokers $(\mathrm{OR}=1.442,95 \% \mathrm{CI}=1.050-1.979, \mathrm{P}=0.025)$, non-drinkers $(\mathrm{OR}=1.430,95 \% \mathrm{CI}=1.072$ $1.907, \mathrm{P}=0.028)$, and individuals with a family history of malignancy $(\mathrm{OR}=1.401,95 \% \mathrm{CI}$ $=1.062-1.849, \mathrm{P}=0.020)$.

Table 3. Stratification analysis of esophageal squamous cell carcinoma (ESCC) risk associated with the rs114673809 polymorphism.

\begin{tabular}{|c|c|c|c|c|}
\hline & \multicolumn{2}{|c|}{ Cases/controls } & \multirow[t]{2}{*}{ OR $(95 \% \mathrm{CI})$} & \multirow[t]{2}{*}{$\mathrm{P}$} \\
\hline & GG & $\mathrm{GA}+\mathrm{AA}$ & & \\
\hline \multicolumn{5}{|l|}{ Age } \\
\hline$<59$ & $79 / 105$ & $114 / 101$ & $1.500(1.009-2.229)$ & 0.045 \\
\hline$\geq 59$ & $118 / 130$ & $137 / 124$ & $1.217(0.859-1.724)$ & 0.228 \\
\hline \multicolumn{5}{|l|}{ Gender } \\
\hline Males & $135 / 166$ & $188 / 158$ & $1.463(1.073-1.996)$ & 0.018 \\
\hline Females & $62 / 69$ & $63 / 67$ & $1.046(0.644-1.701)$ & 0.902 \\
\hline \multicolumn{5}{|c|}{ Smoking status } \\
\hline No & $123 / 169$ & $170 / 162$ & $1.442(1.050-1.979)$ & 0.025 \\
\hline Yes & $74 / 66$ & $81 / 63$ & $1.147(0.719-1.830)$ & 0.634 \\
\hline \multicolumn{5}{|c|}{ Drinking status } \\
\hline No & $118 / 167$ & $164 / 160$ & $1.430(1.072-1.907)$ & 0.028 \\
\hline Yes & $79 / 68$ & $87 / 65$ & $1.152(0.730-1.819)$ & 0.562 \\
\hline \multicolumn{5}{|c|}{ Family history of malignancy } \\
\hline No & $163 / 218$ & $220 / 210$ & $1.401(1.062-1.849)$ & 0.020 \\
\hline Yes & $34 / 17$ & $33 / 15$ & $1.100(0.473-2.557)$ & 0.834 \\
\hline
\end{tabular}

\section{Detection of plasma homocysteine levels}

We next detected plasma homocysteine levels in ESCC cases and controls. We found significantly higher plasma homocysteine levels in the ESCC cases relative to the controls 
(Figure 1A). Furthermore, we observed a significant increase in plasma homocysteine levels in the ESCC cases carrying the AA genotype relative to the ESCC cases carrying the GG genotype (Figure 1B).
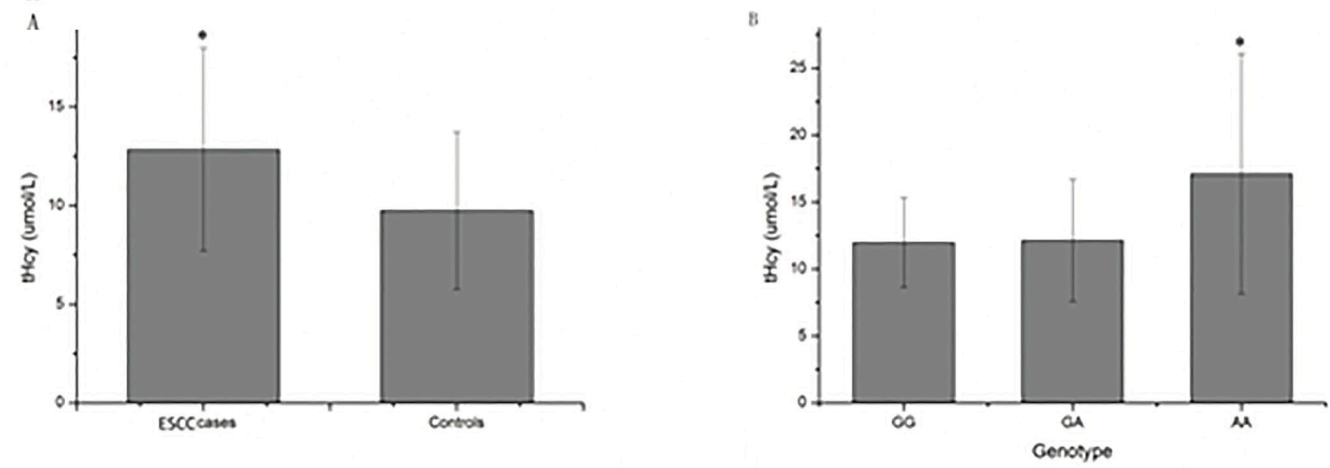

Figure 1. Detection of plasma homocysteine levels. A. Plasma homocysteine levels were detected in esophageal squamous cell carcinoma (ESCC) cases and controls. B. Plasma homocysteine levels were detected in patients with GG, GA, or AA rs114673809 genotypes. *P $<0.05$.

\section{DISCUSSION}

In the current study, we investigated the association between the MTHFR rs114673809 functional SNP and ESCC risk using a case-control approach. We observed that individuals with MTHFR rs114673809 AA genotypes showed significantly increased ESCC risk compared with the GG genotype carriers. These results highlight the involvement of functional genetic variants in miRNA-binding sites in ESCC etiology.

Folic acid (FA) is a major component of leafy green vegetables and citrus fruit, and its deficiency has been implicated in the development of a variety of cancers, including ESCC. FA is thought to play an important role in DNA synthesis and gene activation by influencing DNA methylation and promoting de novo deoxynucleoside synthesis (Choi and Mason, 2000). Several mechanisms could underlie FA deficiency-associated cancers, including aberrant DNA methylation, DNA strand breaks, and impaired DNA repair. MTHFR is the key enzyme involved in FA metabolism and works by modulating the levels of the circulating form of MTHFR, 5-methyl-tetrahydrofolate (5MTHF). The precursor of 5-MTHF(5,10MTHF) is crucial for DNA repair because it provides a supply of the precursors for DNA synthesis (Keld et al., 2014). There are two well-studied polymorphisms of the MTHFR gene: C677T and A1298C (Weisberg et al., 1998). In this study, we found that individuals with MTHFR rs 114673809 AA genotypes showed significantly increased ESCC risk compared with the GG genotype carriers. Several studies have demonstrated that individuals with the MTHFR 677TT genotype have higher plasma homocysteine levels compared with the wild-type MTHFR $677 \mathrm{CC}$, and are therefore associated with diminished genomic DNA methylation, especially when FA intake is insufficient (Li et al., 2005; Wang et al., 2005). In the present study, we observed a significant increase in plasma homocysteine levels in ESCC cases carrying the AA genotype relative to the ESCC cases carrying the GG genotype. Our findings indicate that the MTHFR rs114673809 functional SNP might influence homocysteine levels.

In summary, our results suggest that the functional MTHFR rs114673809 SNP is 
associated with a significantly increased ESCC risk in Chinese populations. Further effort is needed to determine whether the MTHFR rs114673809 genetic polymorphism can be used as a potential diagnostic marker for ESCC.

\title{
Conflicts of interest
}

The authors declare no conflict of interest.

\section{ACKNOWLEDGMENTS}

\author{
Research supported by “Liu Da Gao Feng” Found (\#WSN-118).
}

\section{REFERENCES}

Bandla S, Pennathur A, Luketich JD, Beer DG, et al. (2012). Comparative genomics of esophageal adenocarcinoma and squamous cell carcinoma. Ann. Thorac. Surg. 93: 1101-1106. http://dx.doi.org/10.1016/j. athoracsur.2012.01.064

Choi SW and Mason JB (2000). Folate and carcinogenesis: an integrated scheme. J. Nutr. 130: 129-132.

Fan XJ, Ren PL, Lu ZJ, Zhao S, et al. (2013). [The study of esophageal cancer risk associated with polymorphisms of DNA damage repair genes XRCC4 and RAD51]. Sichuan Da Xue Xue Bao Yi Xue Ban 44: 568-572.

Frantzen F, Faaren AL, Alfheim I and Nordhei AK (1998). Enzyme conversion immunoassay for determining total homocysteine in plasma or serum. Clin. Chem. 44: 311-316.

Holmes RS and Vaughan TL (2007). Epidemiology and pathogenesis of esophageal cancer. Semin. Radiat. Oncol. 17: 2-9. http://dx.doi.org/10.1016/j.semradonc.2006.09.003

Keld R, Thian M, Hau C, Sajid J, et al. (2014). Polymorphisms of MTHFR and susceptibility to oesophageal adenocarcinoma in a Caucasian United Kingdom population. World J. Gastroenterol. 20: 12212-12216. http://dx.doi.org/10.3748/ wig.v20.i34.12212

Li D, Ahmed M, Li Y, Jiao L, et al. (2005). 5,10-Methylenetetrahydrofolate reductase polymorphisms and the risk of pancreatic cancer. Cancer Epidemiol. Biomarkers Prev. 14: 1470-1476. http://dx.doi.org/10.1158/1055-9965.EPI$\underline{04-0894}$

Martin DN, Boersma BJ, Howe TM, Goodman JE, et al. (2006). Association of MTHFR gene polymorphisms with breast cancer survival. BMC Cancer 6: 257. http://dx.doi.org/10.1186/1471-2407-6-257

Mayne ST, Risch HA, Dubrow R, Chow WH, et al. (2001). Nutrient intake and risk of subtypes of esophageal and gastric cancer. Cancer Epidemiol. Biomarkers Prev. 10: 1055-1062.

Saberi S, Zendehdel K, Jahangiri S, Talebkhan Y, et al. (2012). Impact of methylenetetrahydrofolate reductase C677T polymorphism on the risk of gastric cancer and its interaction with Helicobacter pylori infection. Iran. Biomed. J. 16: $179-184$

Vaughan TL, Davis S, Kristal A and Thomas DB (1995). Obesity, alcohol, and tobacco as risk factors for cancers of the esophagus and gastric cardia: adenocarcinoma versus squamous cell carcinoma. Cancer Epidemiol. Biomarkers Prev. 4: 85-92.

Wang L, Miao X, Tan W, Lu X, et al. (2005). Genetic polymorphisms in methylenetetrahydrofolate reductase and thymidylate synthase and risk of pancreatic cancer. Clin. Gastroenterol. Hepatol. 3: 743-751. http://dx.doi. org $/ 10.1016 / \mathrm{S} 1542-3565(05) 00156-4$

Wang YF, Wang XS, Gao SG, Chen Q, et al. (2013). Clinical significance of combined detection of human papilloma virus infection and human telomerase RNA component gene amplification in patients with squamous cell carcinoma of the esophagus in northern China. Eur. J. Med. Res. 18: 11. http://dx.doi.org/10.1186/2047-783X-18-11

Weisberg I, Tran P, Christensen B, Sibani S, et al. (1998). A second genetic polymorphism in methylenetetrahydrofolate reductase (MTHFR) associated with decreased enzyme activity. Mol. Genet. Metab. 64: 169-172. http://dx.doi. org/10.1006/mgme.1998.2714

Xu Y, Ma H, Yu H, Liu Z, et al. (2013). The miR-184 binding-site rs8126 T $>$ C polymorphism in TNFAIP2 is associated with risk of gastric cancer. PLoS One 8: e64973. http://dx.doi.org/10.1371/journal.pone.0064973

Ye B, Feng J, Pan X, Yang Y, et al. (2014). Genetic variant of single-nucleotide polymorphism is associated with risk of esophageal squamous cell carcinoma. Genet. Test. Mol. Biomarkers 18: 45-49. http://dx.doi.org/10.1089/ gtmb.2013.0336 
Zhang X, Wei J, Zhou L, Zhou C, et al. (2013). A functional BRCA1 coding sequence genetic variant contributes to risk of esophageal squamous cell carcinoma. Carcinogenesis 34: 2309-2313. http://dx.doi.org/10.1093/carcin/bgt213

Zhou L, Zhang X, Li Z, Zhou C, et al. (2013). Association of a genetic variation in a miR-191 binding site in MDM4 with risk of esophageal squamous cell carcinoma. PLoS One 8: e64331.http://dx.doi.org/10.1371/journal.pone.0064331 